\title{
Bomb-pulse radiocarbon dating of modern paintings on canvas
}

Fiona Brock ${ }^{1}$, Nicholas Eastaugh ${ }^{2}$, Thierry Ford 3 , Joyce H. Townsend 4 .

1. Cranfield Forensic Institute, Cranfield University, Defence Academy of the UK, Shrivenham, SN6 8LA, UK.

2. Art Analysis and Research Inc., London, SE1 2AN, UK.

3. Conservation Dept., National Museum of Art, Architecture and Design, 0130, Oslo, Norway.

4. Conservation Dept., Tate Britain, Millbank, London SW1P 4RG, UK.

\begin{abstract}
Radiocarbon dating has previously been applied to modern paintings on canvas from the $20^{\text {th }}$ century to identify potential modern forgeries, and dates indicate a time lag of several years between the harvesting of plant fibres for making canvas, and completion of a painting. This study investigated both the length of this time lag and the potential of radiocarbon dating to inform about an individual artist's mode of working (for example long-term storage or re-use of canvases, or extended reworking on a single canvas) and/or to establish a chronology for a corpus of work. Two pre-bomb and 16 post-bomb artworks by 17 mid twentiethcentury Scandinavian artists were radiocarbon dated. The majority of post-bomb samples indicated a time lag of 2-5 years between the harvesting of the plants and completion of a painting, but some samples recorded lags of up to 10 years, and others produced much earlier results, potentially indicating the use of much older canvases or challenges removing contamination prior to dating. The importance of thorough pre-screening of canvas samples for both synthetic fibres and contaminants prior to dating, and selection of the most suitable calibration curve, are highlighted.
\end{abstract}

\section{Introduction}

Radiocarbon dating is traditionally applied to archaeological and (palaeo) environmental studies, but atmospheric nuclear bomb testing in the 1950s and 1960s doubled the concentration of carbon-14 in the atmosphere, resulting in a spike of atmospheric 14C (the 'bomb-pulse') that provides a unique period from 
the mid-1950s onwards during which biological materials can be dated to within just a few calendar years, especially if additional information is available to identify with which side of the bomb curve the calibrated date range is associated (e.g. Tuniz et al., 2004; Zoppi et al., 2004; Hua, 2009).

Bomb-pulse dating has been applied to a range of forensic investigations, including estimating the year of birth and/or date of death for human skeletal remains (e.g. Wild et al., 2000; Spalding et al., 2005; Cook et al., 2015) and the turnover of bodily tissues for medical applications (e.g. Spalding et al., 2008), as well as analysis of wine and whisky vintages (e.g. Schönhofer, 1989; Tuniz et al., 2004), the biological composition of hydrocarbon fuels (e.g. Dijs et al. 2006) and the time of harvest of illicit drugs (e.g. Tuniz et al., 2004; Zoppi et al., 2004).

The application of radiocarbon dating to $20^{\text {th }}$ century artworks has generally focused on the potential of the technique for detecting modern forgeries (e.g. Keisch and Miller, 1972; Caforio et al., 2014). Fedi et al. (2013) and Hendriks et al. (2016, 2018) investigated whether radiocarbon could be used to date contemporary art, with the latter two studies dating both canvas and binder. However, these studies dated works from the start of the $20^{\text {th }}$ century to the 1960s: to our knowledge, no published studies investigate any more recent works with firm dates of use for the canvas used by the artist.

One issue relating to the dating of modern artworks is the identification of the material most likely to provide a reliable date corresponding to the completion of the painting. The wooden stretchers to which canvases are attached are less likely than the canvas itself to be contaminated with carbon of different ages from priming, paint, binders and other organic substances applied by artists, but they may have an 'in-built' age, or the whole stretcher might have been constructed from older, re-purposed wood, or they may be later replacements. Many modern artists' and commercial paints have a shelf life that varies from years to decades, and even if the binder is exclusively plant-based (linseed or safflower oil) its manufacture could pre-date the time of painting by some years. The most commonly explored material for radiocarbon dating of paintings is the canvas support (or paper for watercolours; Keisch and Miller, 1972), but its radiocarbon age will relate to the harvesting of the short-lived plants used to make linen from flax or cotton duck from cotton bolls (with a one-year growth cycle), rather than 
the completion of the painting, resulting in a time lag of several years (Fedi et al., 2013; Caforio et al., 2014; Hendriks et al., 2016). Care is also required to sample canvas that is not contaminated with sizing, priming, paint, varnish, conservation materials, or other organic materials which could affect the date and which might be difficult to remove during pretreatment processes.

Keisch and Miller (1972) and Hendriks et al. (2016) also dated linseed oil a commonly-used basic ingredient of the binder in historic tube paints - recovered from canvas samples and paints. However, dating of linseed oil and other binders requires detailed chemical analysis of adjacent paint samples to ensure no other carbon sources are present, such as organic pigments, varnishes, etc. (Hendriks et al., 2016, 2018), and samples that could be removed from an artwork are likely to be extremely small, making it currently an unsuitable substance for many radiocarbon laboratories to date. It is also possible that, although it is often considered to have a relatively short shelf life, linseed oil that is several years old could be added to tube paint by the artist, resulting in an erroneous date for an artwork.

Regardless of the choice of material for dating, additional information is often required, such as the periods of activity or date of death of the artist, known dates of acquisition (and confirmed retention) of the artwork by trusted sources, or known exhibition and photography of the painting in question, to identify whether calibrated radiocarbon dates are associated with the ascending or descending slope of the bomb curve.

This project was established with the aim of investigating two key questions. Firstly, how long is the time lag between the growth and harvesting of fibres later used to make a canvas, and its use by an artist? Secondly, how could radiocarbon dating inform on an individual artist's mode of work? Could it aid the establishment of a chronology of an artist's work (especially during the rapid evolution that can take place in an artist's early style, which is often accompanied with poor historical documentation)? Could questions be answered about an artist's practise in respect to the length of time over which a specific supply of canvas may have been used and whether paintings may have been reworked over extended periods of time? 
Samples of canvas were collected from 18 mid-twentieth century artworks from the National Museum of Art, Architecture and Design, Oslo, Norway. Of these, two were pre-bomb artworks dating to 1948 and 1951, and the remainder dated to regular intervals throughout the bomb pulse period from 1959 to 1991. Confidence in the dates of painting was supported by known dates of acquisition by the museum, with many works bought directly from the artist (Table 1). Care was taken to choose only canvas made of natural fibres and likely to be artists' quality linen canvas, as any synthetic fibre content would have resulted in an artificially older radiocarbon age. Fibres heavily contaminated with paint and other materials were avoided, and all samples were prescreened with FTIR and polarised light microscopy (PLM) to identify potential contaminants before radiocarbon pretreatment.

\section{Methods \& Materials}

Samples were collected from 18 different paintings, details of which are provided in Table 1. Samples were selected from the paintings' turnover edges, and where possible, from clean and unprimed areas. This was undertaken in order to reduce the risk of contamination with the carbon content of paints. Individual weft-fibre strands were either carefully pulled-off or cut-off with clean microdissecting scissors from the loose and frayed turnover edges. These measured between $8-30 \mathrm{~mm}$ in length with a weight range between 8.2 to $98.9 \mathrm{mg}$ (on average weighing less than $20 \mathrm{mg}$ ).

\section{Insert Table 1 here (or nearby where suitable)}

FTIR: The instrument used was a Bruker Vertex 70 equipped with a mid-infrared source, a potassium bromide $(\mathrm{KBr})$ beamsplitter, a HeNe laser and a deuterated triglycine sulfate detector. The spectrometer was equipped with Pike GladiATR accessory. IR spectra were collected between 4000 and $600 \mathrm{~cm}^{-1}$ using 64, 128 and 256 sample scans and a spectral resolution of $4 \mathrm{~cm}^{-1}$.

Fibre identification by polarising light microscopy (PLM): Fibre samples were dispersed in Cargille Meltmount $\odot$ of refractive index 1.66 and examined on a 
Leica DMRX polarising light microscope at magnifications of 100x to 400x. Fibre identification was performed according to standard procedural methods for longitudinal thread samples, including the modified Herzog test to differentiate bast fibres (Bergfjord and Holst, 2010; Haugan and Holst, 2013).

Radiocarbon dating: Samples were pre-treated and dated at the Oxford Radiocarbon Accelerator Unit (ORAU). Canvas samples were inspected visually, and any surface contaminant was avoided when sampling for dating where possible. If samples were too small to completely avoid surface coatings, as much of the coating as possible was removed mechanically with a clean scalpel. Any woven samples were separated into individual fibres prior to treatment. Samples for dating ranged in size from 4.5 to $21.0 \mathrm{mg}$.

Unless FTIR and PLM analysis prior to pretreatment had identified any specific contaminants, all samples were subject to a routine organic solvent sequence consisting of acetone $\left(45^{\circ} \mathrm{C}, 60-90 \mathrm{~min}\right)$, methanol $\left(45^{\circ} \mathrm{C}, 60-70 \mathrm{~min}\right)$, and chloroform (room temperature, 60-80 $\mathrm{min}$ ). Three separate aliquots of sample MS-03926 were treated, two with this aforementioned solvent wash as part of routine in-house quality assurance procedures, and one without the solvent sequence to determine whether it affected the date at all. Sample MS02190 was also dated twice for quality assurance purposes, undergoing the same solvent sequence in both cases.

Several potential contaminants, including PVA, were detected by FTIR on two samples (MS-02871 and MS-02577), and the solvent wash was adapted to include the routine ORAU in-house procedure for PVA removal as follows: ultrapure Milli- $\mathrm{Q}^{\mathrm{TM}}$ water $\left(50^{\circ} \mathrm{C}, 105 \mathrm{~min}\right.$ for MS-02871, 4 hours for MS02577); acetone $\left(45^{\circ} \mathrm{C}\right.$, two separate washes of 2 hours and 75 min each for MS-02871, 2 x 2 hour washes for MS-02577); methanol $\left(45^{\circ} \mathrm{C}, 2\right.$ hour $\left.45 \mathrm{~min}\right) ; 1: 1$ methanol: chloroform (room temperature, $70 \mathrm{~min}$ ).

After thorough drying for a minimum of overnight, each sample then underwent routine ABA (acid-base-acid) pretreatment (lab code UV* in Brock et al., 2010) as follows: hydrochloric acid $\left(1 \mathrm{M}, 80^{\circ} \mathrm{C}, 20 \mathrm{~min}\right)$; sodium hydroxide $\left(0.2 \mathrm{M}, 80^{\circ} \mathrm{C}, 20 \mathrm{~min}\right)$; hydrochloric acid $\left(1 \mathrm{M}, 80^{\circ} \mathrm{C}, 1\right.$ hour $) ; 2.5 \% \mathrm{wt} /$ vol sodium chlorite at $\mathrm{pH} 3\left(80^{\circ} \mathrm{C}, 5-15 \mathrm{~min}\right.$ depending on the integrity of the sample). The 
samples underwent thorough washing with ultrapure water after each step. After pretreatment, samples were freeze-dried, combusted, $\mathrm{CO}_{2}$ cryogenically distilled prior to graphitisation and accelerator mass spectrometry (AMS) radiocarbon dated as described by Brock et al. (2010).

\section{Results \& Discussion}

It was important to ensure that the samples dated in this study were natural fibres, as any synthetic content would likely be petroleum-based (and hence radiocarbon-dead) and would result in an erroneously old date. Visual inspection established that the canvases were all of artists' quality, and hence likely to be linen made from flax fibres. FTIR and PLM analysis demonstrated that all 18 samples in this study were natural cellulose-based, although one was identified to be linen/hemp (MS-02871) and two cotton (MS-01635, MS-02577). Full fibre identifications will be discussed further in Eastaugh et al. (forthcoming).

FTIR analysis detected potential contaminants in 12 of the samples. Calcite was detected on 4 (MS-02190, MS-02548, MS-02948, MS-02953) and aragonite on sample MS-02577. Traces of oil were detected in samples MS-02948, MS-02548, MS-02953, MS-02577, MS-02190, MS-03926, MS-00418, MS-02115, MS-01635 and MS-02663. Polyvinyl acetate (PVA) was detected on MS-02575, MS-02577 and MS-02871, a protein (probably an animal glue) on MS-02663, metal soaps on MS-02948, MS-02953, MS-02190, MS-00418, MS-02115, MS-02663, MS-02548 and MS-01635, and pigments including lead carbonate (on MS-02190 and MS02663) and goethite, probably from an earth pigment (on MS-02948 and MS02577). No contaminants were detected on MS-04056, MS-02876, MS-03595, MS02883, MS-02781 and MS-00415.

For all samples, any visible contaminant was avoided when sampling prior to radiocarbon pretreatment, or removed mechanically with a clean scalpel if necessary. Traces of calcite or aragonite, as well as lead carbonates, would have been removed during the acid stage of the pretreatment. The chloroform (or methanol/chloroform mix) stages of pretreatment should have removed any oil or grease, including human fingerprints. It is extremely difficult to remove PVA completely due to cross-linking with the canvas fibres (Brock et al. 2018), but ORAU's in-house PVA-removal solvent extraction protocol involving water and 
acetone washes was employed for MS-02577 and MS-02871 (although not for MS02575, where PVA was not detected until re-analysis of remaining untreated canvas by FTIR and PLM after dating). Metal soaps which form through interaction between pigment and paint medium as paint ages and degrades, have the same radiocarbon origin as the paint medium. Goethite is an iron oxyhydroxide mineral that does not contain carbon, and so its removal was not vital prior to radiocarbon dating. Any particulate matter loosely attached to the surface of the painting, such as skin flakes or other dirt, would most likely have been dislodged and decanted off during the multiple organic and aqueous washes during pretreatment, although no such materials were observed by PLM. It should be noted that, as all 18 artworks were framed and sampling was undertaken from the turnover edges of each canvas, the material dated had a degree of protection from excessive human contact and hence contamination.

Radiocarbon dates were calibrated using OxCal v4.2.4. (Bronk Ramsey 2009) and calibrated date ranges are given in Table 2. All samples that gave F14C results (i.e. post 1950AD) were calibrated using the Bomb 13 NH1 curve (Hua et al., 2013). Those with pre-bomb dates were calibrated using IntCal13 (Reimer et al. 2013). For all post-bomb samples except those from the apex of the bomb-peak (ca. 1963-1965 AD), a minimum of 2 calibrated date ranges are given, corresponding to the ascending and descending slopes of the curve. For many samples, the date of acquisition of the new painting directly from the artist, by the museum, excludes one of these date ranges.

\section{Insert Table 2 here (or nearby where suitable)}

The two samples signed before the influence of nuclear bomb testing (MS02948, signed in 1948, and MS-04056, signed in 1951) gave pre-bomb dates as expected, of $221 \pm 20 \mathrm{BP}$ and $250 \pm 20 \mathrm{BP}$, respectively. While calibration with IntCal13 gives feasible dates for MS-02948, the calibrated date for MS-04056 demonstrates the difficulty of dating materials at the boundary between the IntCal and bomb calibration curves. Figure 1a shows the date calibrated with IntCal13, where the dates are clearly too old for the specimen (ranging from the $16^{\text {th }}$ to $18^{\text {th }}$ centuries), especially as no synthetic component was detected within the textiles fibres by FTIR or PLM. 

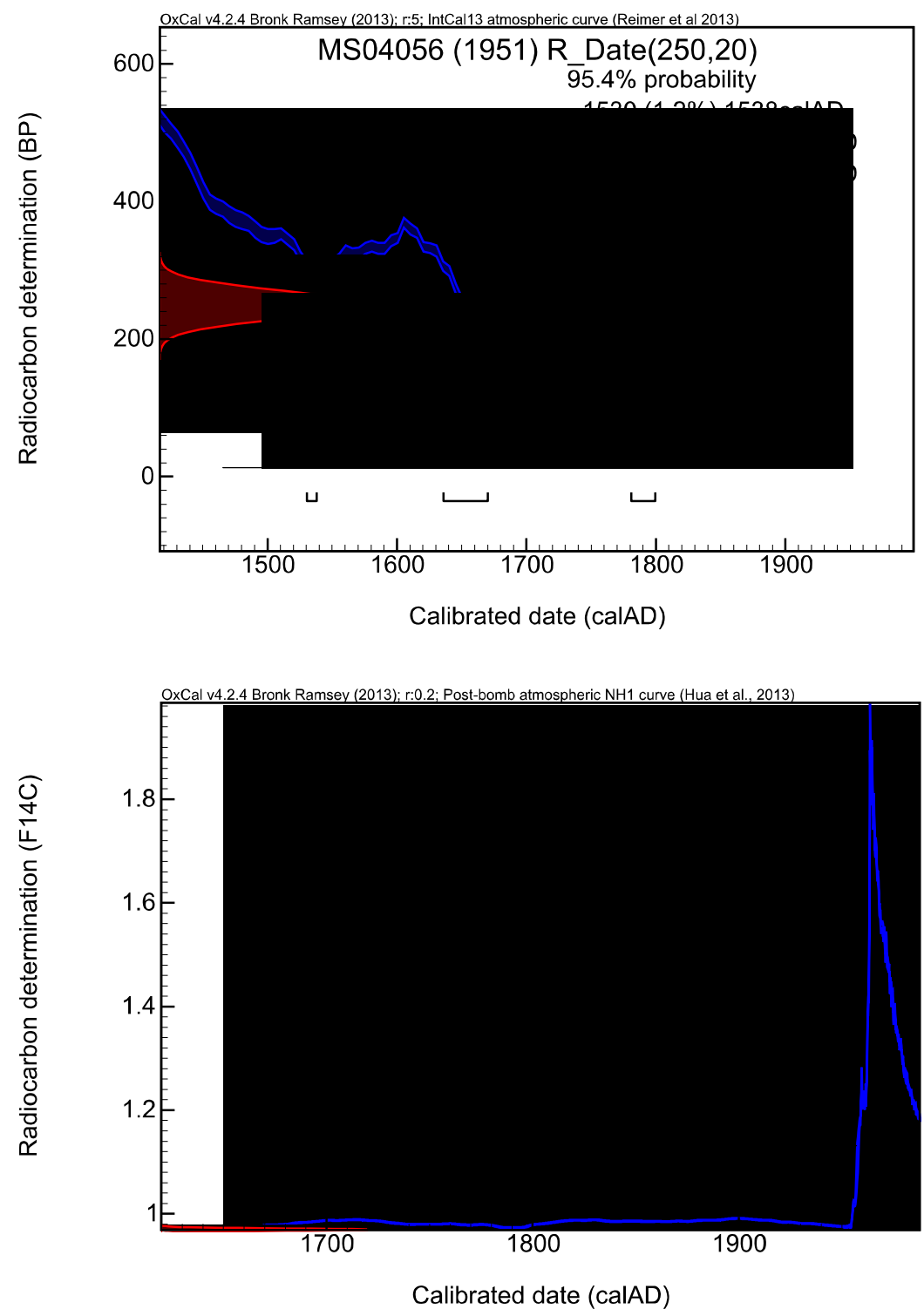

Figure 1. Sample MS-04056, dating to 1951, calibrated using IntCal13 (Fig. 1a) and post-bomb $13 \mathrm{NH} 1$ curve (Figure 1b).

Of the 16 post-bomb artworks (dating from 1959 onwards), a total of 9 gave calibrated date ranges of 1-5 years before the date of painting. Four of these paintings also gave calibrated date ranges that could be excluded as they were after the date of acquisition by the museum. The calibrated time periods from the ascending slope of the curve were excluded for three other samples on the assumption that it was unlikely that 14-15 years (MS-02190), 18 years (MS00418) or 32-33 years (MS-03594) had passed since the harvesting of the plant and the completion of the artwork. 
It is likely that the minimum time period between the harvesting of the crop and the final dating of the painting would be around 2 years, to allow for harvesting, lengthy processing (retting) of fibres that constituted a raw material unobtainable for a further 12 months, spinning into thread, weaving, sizing and priming in bulk, cutting and stretching, packaging, sale and transport to an artists' supply shop, stock retention, purchase by the artist, and (sometime later) selection by the artist of a canvas for a given subject. This is consistent with the findings of Hendriks et al. $(2016,2018)$ who reported calibrated dates of 4-5 years before completion of three paintings from the early 1960 s.

Two samples were observed to have longer time lags between the harvesting of the crop and the completion of the painting, MS-02663 (6-8 years) and MS02115 (8-10 years), which could indicate either long-term storage of the canvas by retailer or artist, or extended reworking of the paintings by the artists. Traces of oil were observed by FTIR on both these canvas samples prior to dating, most likely from binders such as linseed oil, rather than petroleum-derived, radiocarbon-dead sources. While it is expected that this oil would have been removed during pretreatment, the possibility that trace levels remained cannot be completely excluded. However, it is highly unlikely that oil that was significantly older than the canvas remained in sufficient quantities after pretreatment to have resulted in the extended time lags between harvesting and painting observed in these instances.

Three samples, however, gave pre-bomb dates of $270 \pm 25$ BP (MS-02548), $276 \pm 25$ BP (MS-02575) and $307 \pm 24$ BP (MS-02781). The calibrated date ranges are not consistent with artworks from the $20^{\text {th }}$ century, and may indicate residual contamination of the fibres after pretreatment (especially as PVA was detected on both MS-02575 and MS-02781, and oil on MS-02548). The dates are consistent with a synthetic component to the fibre of around $40 \%$, but it is unlikely that either oil or PVA was present in such high quantities, and neither FTIR or PLM detected the presence of synthetic fibres in any of these canvases. In other circumstances, forgers have been known to apply new paint to old canvases in order to foster an appearance of age: this would lead to a much older radiocarbon date than the proposed date of painting. In these instances, however, it is more likely that the artists were working on older canvases. 
One sample in particular, MS-02577, requires further consideration. The painting is signed 1966, but the canvas fibres give a calibrated date range of 19651966 calAD (95.4\% probability). It is highly unlikely that the crop would have been harvested and an artist's canvas manufactured and used within such a short time period. One possibility is that the 'canvas' was an inferior, rapidly-produced textile, especially as the fibres were identified by PLM to be cotton, unlike the majority of other canvases in this study. The $\delta^{13} \mathrm{C}$ value of $-22.9 \%$ is also an outlier compared to the measurements on all the other samples. Although this sample was one of the more heavily contaminated canvases, most chemicals applied to the canvas would either have been of a similar age to the canvas fibres (e.g. plant-based oils in paints or varnishes) or radiocarbon-dead (e.g. some varnishes, waxes or PVA), the presence of which would have resulted in an artificially old age. It would be extremely unlikely, if not impossible, for contamination to have produced a date too close to the time of completion of the painting.

The narrow timeframe between the calibrated date range and the date of the painting could, instead, be due to assumptions made within the calibration curve itself. The atmospheric ${ }^{14} \mathrm{C}$ measurements used within the calibration curve dataset are deliberately taken in clean-air regions to exclude potential anthropogenic/industrial contributions, but it is unlikely that all potential canvasfibre crops are grown in such remote locations. Just a small (e.g. 0.5\%) contribution of radiocarbon-dead contamination in an area of heavy industry could potentially be sufficient to shift the calibrated date by 1 or 2 years. This particular piece dates to just after the peak of the bomb curve in 1963, and the height of the period of atmospheric nuclear testing, and so it might also be possible that the date could be affected by the steep tropospheric gradients in atmospheric ${ }^{14} \mathrm{C}$ at that time.

The assumption that the canvas fibre was locally-grown may also not be justified in a global economy. High-quality artists' materials purchased in Scandinavia are very likely to have been imported from one of the traditional artists' colourmen, none of whom were based in Scandinavia. Companies such as Winsor \& Newton, founded in the nineteenth century, had established large export markets world-wide during that period and continued to trade during the mid- 
twentieth century, from factories then largely based in the UK. Scandinavian or Norwegian manufacturers of canvas might not have concentrated exclusively on artists' materials, and might have treated their products for alternative end-uses such as packaging or sail-making.

Taking the $\delta^{13} \mathrm{C}$ value, the identification of the fibres as cotton, and the calibrated date into consideration, it is likely that this canvas was made from fibres from a different geographical region, with different growing conditions, to the other canvases in this study. The Bomb13 NH1 calibration curve was chosen arbitrarily for this study given that the artworks were all by Scandinavian artists, and hence well within the $\mathrm{NH} 1$ region above $40^{\circ} \mathrm{N}$ (as defined by Hua et al., 2013). However, the location of the artists is not necessarily a reliable indicator of the location of the canvas fibre crop, and this particular canvas may have originated in the $\mathrm{NH} 2$ region (between $40^{\circ} \mathrm{N}$ and the mean summer intertropical convergence zone), or even the NH3 region (the northern hemisphere intertropical convergence zone), as defined by Hua et al. (2013). Gunderson, the artist of MS-02577, was known to travel widely in Europe in the 1940s and 50s, including as far south as Portugal, parts of which would fit into the NH2 region. It is therefore not impossible that he sourced his canvases made from fibres grown in different regions to his contemporaries in Scandinavia. Calibration of the date for this sample using the Bomb13 $\mathrm{NH} 2$ curve (Figure 2) gives potential dates of $1963(9.1 \%)$ and $1964(7.4 \%)$ as well as 1965-66 (79.0\%), and hence a more feasible lag between the harvesting of the crop and completion of the painting of up to 3 years. 

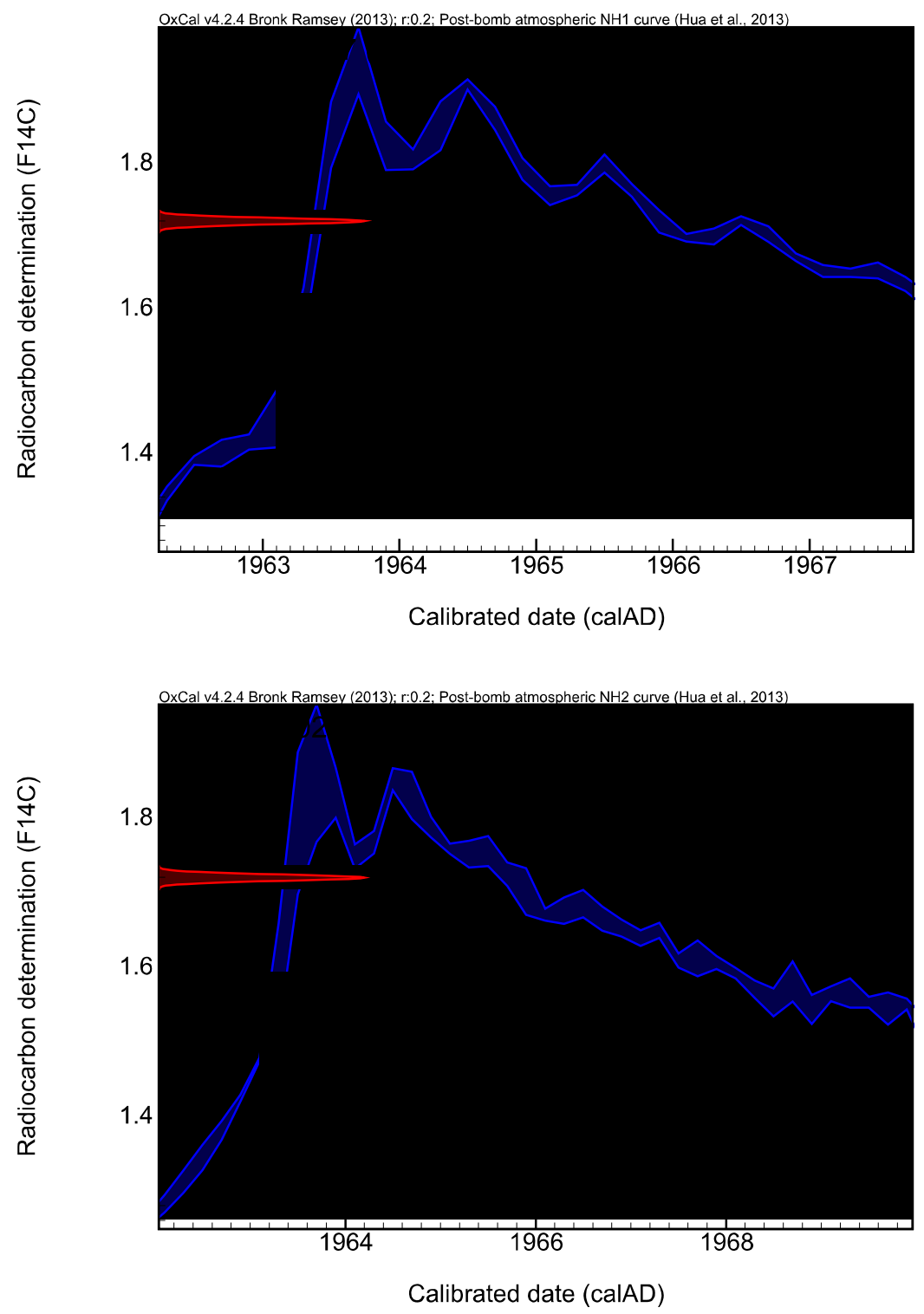

Figure 2. Sample MS-02577, completed in 1966, gives slightly different calibrated dates ranges with bomb curves NH1 (fig 1a) and NH2 (fig. 1b).

Radiocarbon dates on a wider selection of works by the artist responsible for this painting, as well as the two with considerable time lags between the dates of the canvas and the finished artworks (MS-02663 and MS-02115), could provide useful insight into different working regimes of these artists compared to those whose paintings had the more common time lag of 2-5 years from the age of the canvas fibres.

It is important to note that radiocarbon dating within the bomb-pulse period, and the transition into the period in the early 1950s, can be challenging, due to both the resolution involved (calibrating to within a single calendar year in 
some instances) and the difficulties in establishing calibration datasets at such resolution. For consistency, all dates within this study were calibrated using default settings in $0 x$ Cal with IntCal13 and post-bomb atmospheric curves NH1 and NH2. However, in some instances the use of other calibration packages e.g. Calib or CaliBomb (Stuiver et al., 2018), or previous datasets such as IntCal09, may result in slight variations in calibrated calendar year date ranges. Even within OxCal, using a finer resolution than the default value of 0.2 year, will further refine the calibrated dates. These issues must be considered carefully when dating materials post-1950, and it is vital that supporting information is taken into account when calibrating and interpreting dates.

\section{Conclusion}

The majority of the post-bomb artworks in this study demonstrated a time lag of 2-5 years between the harvesting of the crop utilised in the canvas and the completion and (optional) signing of the piece. This is a realistic time frame for harvesting, processing of fibres, retail, and selection by the artist of a canvas for a given subject. However, several artworks gave older, pre-bomb dates despite the apparent lack of synthetic fibres in the canvas, that are unlikely to be entirely due to the presence of trace levels of residual contamination from substances such as PVA. Thorough analysis of samples prior to dating - preferably by FTIR and microscopy - is recommended to identify potential sources of contamination that may affect the date of a canvas.

This study demonstrates the importance of applying the correct calibration curve to samples of modern art, and the appreciation of potential geographical origins of canvas fibres, especially in relation to the dataset used to define the calibration curve itself. Samples dating to the early 1950s and the switch from prebomb (e.g. IntCal13) to bomb-curve calibration data sets appear difficult to calibrate reliably. Different calibration software packages (e.g. OxCal, Calib) can also provide slightly different calibrated date ranges for the same date using the same calibration dataset depending on the default resolution settings, which may be significant for samples such as these where precision can be measured to just 1 or 2 calendar years. The museum acquisition date (as well as the date of death of the artist, or any date beyond which (s)he could not paint) can be particularly 
useful for identifying the correct calibrated date period for a sample, by potentially eliminating either the ascending or descending slope of the bomb curve. Radiocarbon dating may be less informative for a painting with no associated information, but may still be useful for identifying potential modern forgeries, by demonstrating the production of a fundamental component of the artwork after the death of the suggested artist or acquisition of the piece.

Given the common time lag of 2-5 years between a canvas and the completion of a painting, radiocarbon dating appears unlikely to be suited to identifying the precise chronology of a specific artist's corpus. But the identification of shorter or considerably larger time lags may indicate a different approach by an individual artist from their peers, or a deviation from their normal practice, and in some instances may justify further canvas analysis and/or dating of the artist's corpus to provide more information about their mode of working.

\section{Acknowledgements}

The radiocarbon dating was funded by NRCF grant NF/2013/1/5 Investigating the potential of bomb-pulse radiocarbon dating to study culture heritage and modern art (short-form title Modern Art), and undertaken by FB while employed at the Oxford Radiocarbon Accelerator Unit. Bhavini Vaghji and Joanna Russell are thanked for their assistance with canvas pre-screening by FTIR and PLM, respectively. Christopher Bronk Ramsey is thanked for helpful discussions about calibrating modern radiocarbon dates.

\section{References}

Bergfjord C, Holst B. 2010. A procedure for identifying textile bast fibres using microscopy: flax, nettle/ramie, hemp and jute. Ultramicroscopy 110: 11921197.

Brock F, Higham T, Ditchfield P, Bronk Ramsey C. 2010. Current pretreatment methods for AMS radiocarbon dating at the Oxford Radiocarbon Accelerator Unit (ORAU). Radiocarbon 52(1) 103-112.

Brock F, Dee M, Hughes A, Snoeck C, Staff R, Bronk Ramsey C. 2018. Testing the effectiveness of protocols for removal of common conservation treatments for radiocarbon dating. Radiocarbon 60(1): 35-50. 
Bronk Ramsey C. (2009). Bayesian analysis of radiocarbon dates. Radiocarbon 51(1): 337-360.

Caforio L, Fedi ME, Mandò PA, Minarelli F, Peccenini E, Pellicori V, Petrucci FC, Schwartzbaum P, Taccetti F. 2014. Discovering forgeries of modern art by the ${ }^{14} \mathrm{C}$ bomb peak. Eur. Phys. J. Plus 129: 6.

Cook GT, Ainscough LAN, Dunbar E. 2015. Radiocarbon analysis of modern skeletal remains to determine year of birth and death - a case study. Radiocarbon 57(3): 327-336.

Dijs IJ, van der Windt E, Kaihola L, van der Borg K. 2006. Quantitative determination by ${ }^{14} \mathrm{C}$ analysis of the biological component in fuels. Radiocarbon 48: 315-323.

Eastaugh N, Brock F, Ford T, Townsend JH. The potential for dating canvas from mid-20th century paintings using post-bomb radiocarbon. In preparation.

Fedi ME, Caforio L, Mandò PA, Petrucci F, Taccetti F. 2013. May ${ }^{14} \mathrm{C}$ be used to date contemporary art? Nuclear Instruments \& Methods in Physics Research B 294: 662-665.

Haugan E, Holst B 2013. Determining the fibrilar orientation of bast fibres with polarized light microscopy: the modified Herzog test (red plate test) explained. Journal of Microscopy 252: 159-168.

Hendriks L, Hajdas I, McIntyre C, Küffner M, Scherrer NC, Ferreira ESB. 2016. Microscale radiocarbon dating of paintings. Appl. Phys. A. 122:16

Hendriks L, Hajdas I, Ferreira ESB, Scherrer NC, Zumbühl S, Küffner M, Wacker L, Synal H-A, Günther D. 2018. Combined ${ }^{14} \mathrm{C}$ analysis of canvas and organic binder for dating a painting. Radiocarbon 60(1): 207-218.

Hua Q. 2009. Radiocarbon: a chronological tool for the recent past. Quaternary Geochronology 4: 378-390.

Hua Q, Barbetti M, Rakowski AZ. 2013. Atmospheric radiocarbon for the period 1950-2010. Radiocarbon 55: 2059-2072.

Keisch B, Miller H.M. 1972. Recent art forgeries: Detection by C-14 measurements. Nature 240: 491-492.

Reimer PJ, Bard E, Bayliss A, Beck JW, Blackwell PG, Bronk Ramsey C, Grootes PM, Guilderson TP, Haflidason H, Hajdas I, Hatté C, Heaton TJ, Hoffman DL, Hogg AG, Hughen KA, Kaiser KF, Kromer B, Manning SW, Niu M, Reimer RW, Richards 
DA, Scott EM, Southon JR, Staff RA, Turney CSM, van der Plicht J. 2013. IntCal13 and Marine13 Radiocarbon age calibration curves 0-50,000 years cal BP. Radiocarbon 55(4)

Schönhofer F. 1989. Determination of 14C in alcoholic beverages. Radiocarbon 31: 777-784.

Spalding KL, Buchholz BA, Bergman L-E, Druid H, Frisén. 2005. Forensics: Age written in teeth by nuclear tests. Nature 437: 333-334.

Spalding KL, Arner E, Westermark PO, Bernard S, Buchholz BA, Bergmann O, Blomqvist L, Hoffstedt J, Näslund E, Britton T, Concha H, Hassan M, Rydén M, Frisén J, Arner P. 2008. Dynamics of fat cell turnover in humans. Nature 453: 7837.

Stuiver M, Reimer RJ, Reimer RW. 2018. Calib 7.1 [www program] at http://calib.org.

Tuniz C, Zoppi U, Hotchkis MAC. 2004. Sherlock Holmes counts the atoms. Nucl. Instr. Meth B. 213: 469-475.

Wild EM, Arlamovsky KA, Golser R, Kutschera W, Priller A, Puchegger S, Rom W, Steier P, Vycudilik W. 2000. ${ }^{14} \mathrm{C}$ dating with the bomb peak: An application to forensic medicine. Nuclear Instruments and Methods in Physics Research B 172: 944-950.

Zoppi U, Skopec Z, Skopec J, Jones G, Fink D, Hua Q, Jacobsen G, Tuniz C, Williams A. 2004. Forensic applications of ${ }^{14} \mathrm{C}$ bomb-pulse dating. Nucl. Instr. Meth. B. 223-224: 770-775. 


\begin{tabular}{|l|l|l|l|l|}
\hline Sample no. & Artist & Title & Date signed & $\begin{array}{l}\text { Acquisition } \\
\text { date }\end{array}$ \\
\hline MS-02948 & Egil Jacobsen (1910-1998) & Maske i blått rom (Masks in a blue room) & 1948 & $1975^{1}$ \\
\hline MS-04056 & Anna-Eva Bergman (1909-1987) & Composition Finmark impression, No. 35 & 1951 & $1988^{2}$ \\
\hline MS-02871 & Jakob Weidemann (1923-2001) & Høstløv (Autumn leaves) & 1959 & 1985 \\
\hline MS-02548 & Ludvig Eikaas (1920-2010) & Synnøve (Portrait of Synnøve Anker Aurdal) & 1959 & 1967 \\
\hline MS-01635 & Gudrun Kongelf (1909-1987) & Komposisjon (Composition) & 1960 & $1961^{3}$ \\
\hline MS-02883 & Roar Wold (1926-2001) & Ved strandkanten (Along the Beach) & 1963 & 1963 \\
\hline MS-02781 & Inger Sitter (1929-2015) & In the Picture & 1964 & 1979 \\
\hline MS-02953 & Asker Jorn (1941-1973) & Betrængte komplekser (Depressed complex) & 1964 & 1965 \\
\hline MS-02575 & Gunnar S Gundersen (1921-1983) & Komposisjon (Composition) & 1965 & $1965^{1}$ \\
\hline MS-02577 & Gunnar S Gundersen (1921-1983) & Grått rom (Grey room) & 1966 & 1972 \\
\hline MS-02663 & Arne Malmedal (1937- ) & Vestland (Western Norway) & 1967 & 1972 \\
\hline MS-00415 & Thore Heramb (1916-2014) & Ettermiddagskaffe (After dinner coffee) & 1968 & 1968 \\
\hline MS-03926 & Irma Salo Jæger (1928- ) & Verdensflagg (World Flag) & 1968 & 19971 \\
\hline MS-02876 & Frans Widerberg (1934-2017) & Hevnerne (Revenge) & 1972 & 1972 \\
\hline MS-02190 & Håkon Bleken (1929- ) & Ringen sluttet (The circle closes) & 1977 & $1990^{1}$ \\
\hline
\end{tabular}




\begin{tabular}{|l|l|l|l|l|}
\hline MS-00418 & Johs Rian (1891-1981) & Kontraster mot sort (Contrasts against black) & 1980 & 1988 \\
\hline MS-02115 & Ida Lorentzen (1951- ) & Corner Arrangement & 1987 & 1989 \\
\hline MS-03594 & Lena Cronqvist (1938- ) & Ride, ride ranke I (Horsey, horsey, I) & 1991 & 1993 \\
\hline
\end{tabular}

Table 1. Artworks sampled for this study from the National Museum of Art, Architecture and Design, Oslo, including the dates of birth and death of the artist, date of completion of the painting and the date of acquisition by the museum. ${ }^{1}$ Acquired directly from artist. ${ }^{2}$ Acquired from Foundation Bergmann. ${ }^{3}$ Acquired from artist's exhibition. 


\begin{tabular}{|c|c|c|c|c|}
\hline Sample no. & Date painted & $\mathrm{F}^{14} \mathrm{C} / \mathrm{BP}$ & Calibrated date range (calAD) & $\delta^{13} \mathrm{C}(\% 0)$ \\
\hline MS-02948 & 1948 & $221 \pm 20$ & $\begin{array}{l}1645-1679(42.0 \%), 1764-1800 \text { (43.4\%), 1939-... } \\
(10.0 \%)\end{array}$ & -25.4 \\
\hline MS-04056 & 1951 & $250 \pm 20$ & $\begin{array}{l}1530-1538 \text { (1.2\%), } 1636-1670 \quad(76.4 \%), 1781- \\
1799 \text { (see Fig. } 1 \text { ) }\end{array}$ & -25.5 \\
\hline MS-02871 & 1959 & $1.03162 \pm 0.00319$ & $1955-1957(95.4 \%)$ & -26.6 \\
\hline MS-02548 & 1959 & $270 \pm 25$ & $\begin{array}{l}1521-1577(36.1 \%), 1584-1591 \quad(1.2 \%), 1625- \\
1668(53.7 \%), 1783-1797(4.4 \%) .\end{array}$ & -26.0 \\
\hline MS-01635 & 1960 & $1.05476 \pm 0.00297$ & 1956-1957 (3.6\%), 2006...calAD (91.5\%) & -24.4 \\
\hline MS-02883 & 1963 & $1.17984 \pm 0.00329$ & 1958-1959 (23.0\%), 1986-1989(72.4\%) & -25.0 \\
\hline MS-02781 & 1964 & $307 \pm 24$ & 1493-1602 (72.6\%), 1615-1649 (22.8\%) & -25.8 \\
\hline MS-02953 & 1964 & $1.38872 \pm 0.00380$ & $1962(49.0 \%), 1973(1.2 \%), 1974-1975(45.2 \%)$ & -25.1 \\
\hline MS-02575 & 1965 & $276 \pm 25$ & $\begin{array}{l}1520-1593(47.5 \%), 1619-1665 \text { (46.3\%), 1785- } \\
1794(1.6 \%)\end{array}$ & -25.8 \\
\hline MS-02577 & 1966 & $1.71972 \pm 0.00421$ & 1965-1966 (95.4\%) (See Fig. 2) & -22.9 \\
\hline MS-02663 & 1967 & $1.22086 \pm 0.00359$ & 1959-1961 (29.8\%), 1983-1985 (65.6\%) & -25.9 \\
\hline MS-00415 & 1968 & $1.80704 \pm 0.00470$ & $1963-1965(95.4 \%)$ & -25.5 \\
\hline
\end{tabular}




\begin{tabular}{|l|l|l|l|l|}
\hline MS-03926 & 1968 & $\begin{array}{l}1.80624 \pm 0.00405 \\
1.78772 \pm 0.00397 \\
1.79760 \pm 0.00381 *\end{array}$ & $\begin{array}{l}1963-1965(95.4 \%) \\
1963-1965(95.4 \%) \\
1963-1965(95.4 \%)\end{array}$ & -25.6 \\
& & $1.58022 \pm 0.00378$ & $1967-1968(95.4 \%)$ & -25.4 \\
\hline MS-02876 & 1972 & $1.43659 \pm 0.00382$ & $1962-1963(6.2 \%), 1972-1974(89.2 \%)$ & -26.3 \\
\hline MS-02190 & 1977 & $1.44228 \pm 0.00385$ & $1962-1963(4.1 \%), 1972-1974(91.3 \%)$ & -25.9 \\
\hline MS-00418 & 1980 & $1.31206 \pm 0.00363$ & $1962(1.5 \%), 1977-1979(93.9 \%)$ & -26.3 \\
\hline MS-02115 & 1987 & $1.32535 \pm 0.00360$ & $1977-1979(95.4 \%)$ & -26.5 \\
\hline MS-03594 & 1991 & $1.17569 \pm 0.00342$ & $1958-1959(24.0 \%), 1987-1989(71.4 \%)$ & -26.3 \\
\hline
\end{tabular}

Table 2. Radiocarbon dates, $\delta^{13} \mathrm{C}$ measurements, and calibrated date ranges for each sample. All dates were calibrated using 0xCal v.4.2.4 and the IntCal13 dataset for pre-bomb dates (Reimer et al. 2103) and Bomb13 NH1 curve (Qua et al. 2013) for F14C dates. Cross-out calibrated date ranges are not possible, dating to later than the time of acquisition by the museum.* Samples dated without initial solvent pretreatment. 
